Jaime Mena de Torres *

\title{
La fotograffa artística como referente en la visualización del espacio escolar
}

Jaime Mena de Torres é Doutor em Artes e Educação (credenciado pela ANECA), Mestre em Artes e Educação e Bacharel em História da Arte. Atuou como professor colaborador no mestrado interuniversitário de Artes Visuais e Educação (Universidade de Granada). É professor do Departamento de Didática de Artes Plásticas e Visuais da Universidade Internacional de La Rioja (UNIR). <jmenadetorres@gmail.com > ORCID: 0000-0003-3586-5234
Resumen En este articulo la fotografía artística se presentará como enfoque metodológico para el concepto visual de la educación fundamentalmente de dos formas: en primer lugar, propondremos la validez e influencia de la información estética por encima de la información documental en las investigaciones educativas basadas en imágenes; en segundo lugar, a través de un ensayo visual, propondremos diversas composiciones visuales acerca de cuatro temas fundamentales para la construcción del concepto de educación. Los artistas visuales en fotografía han tratado el ámbito escolar de forma recurrente, produciendo una amplia colección de imágenes educativas que trasciende el valor documental de la fotografía. Nuestra hipótesis es que éstas imágenes pueden ser determinantes en nuestras intuiciones e ideas acerca de la escuela y la educación. En el trabajo que presentamos a continuación, distinguimos entre fotografía artística y documental fundamentalmente para señalar la decisiva influencia que puede tener el uso explícito de la información estética por encima del recurso al realismo referencial del que hace uso la fotografía documental. La más clara evidencia la muestra el impacto que han tenido las imágenes de los artistas a lo largo de la historia de la educación. Por otro lado, nuestro discurso visual se estructura en base a cinco foto-ensayos, organizados en base a dos fotografías del autor con dos citas visuales de la historia de la fotografía. Estos han sido compuestos fotoensayos contraponiendo los cuatro principales temas que la fotografía ha preferido tradicionalmente: el espacio escolar, el alumnado, el profesor y las interacciones entre ellos. En los fotoensayos que presentamos a continuación, proponemos lecturas cruzadas entre estos cuatro temas. El resultado de estas interferencias visuales y asociaciones libres propone algunas conclusiones visuales de nuestro estudio.

Palabras clave Investigación Educativa basada en las Artes Visuales, Fotografía, Educación, Artes Visuales. 


\section{Art photography as a reference in the viewing of educational spaces}

Abstract In this paper artistic photography will be presented as a methodological approach to the visual concept of education mainly in two ways: first, we propose photography as an aesthetic value in documentary information within image-based educational research; second, through a visual essay, we will propose different visual compositions about four key issues for the construction of the visual school concept. Artists interested in photography have approached the school and education creating an extensive visual archive since the late 19th century. Beyond the documentary value of these images, we hypothesize that these images can be important to our intuitions and ideas about school and education. In the work that follows, we distinguish between art photography and documentary photography, basically to point out the predominance of aesthetic information above the use of referential realism that prefer documentary photography. On the other hand, our visual discourse is structured around five photo essays, organized each one with two photographs made by the author along with two visual quotations in the history of photography. These photo-essays have been organized by contrasting the four main topics that documentary and art photography has traditionally preferred: the school environment, the students, the teachers and the interactions between them. In the following photo-essays, we propose cross-readings between these four themes. The result of these visual interference and free associations offers some visual findings of our study.

Keywords Educational Visual Art Based Research, Photography, Education, Visual Arts. 


\section{A fotografia artística como referência para a visualização do espaço escolar}

Resumo Neste artigo, a fotografia artística como enfoque metodológico para um conceito visual da educação, será apresentada fundamentalmente de duas formas: em primeiro lugar, propormos a validade e influencia da informação estética para além da informação documental nas investigações educativas baseadas em imagens; em segundo lugar, através de um ensaio visual, proporemos diversas composições visuais em torno de quatro temas fundamentais para a construção do conceito de educação. Os artistas visuais da área da fotografia têm tratado o âmbito escolar de forma recorrente, produzindo uma ampla coleção de imagens educativas que transcende o valor documental da fotografia. A nossa hipótese é que estas imagens podem ser determinantes nas nossas instituições e nas ideias acerca da escola e da educação. No trabalho que apresentamos em seguida fazemos distinção entre fotografia artística e documental fundamentalmente para assinalar a decisiva influência que pode ter o uso explícito da informação estética para além do recurso ao realismo referencial do qual faz uso a fotografia documental. A mais clara evidência disso é mostrada pelo impacto que as imagens dos artistas tiveram na educação ao longo da história. Por outro lado, o nosso discurso visual estrutura-se com base em cinco foto-ensaios, organizados com base em duas fotografias do autor com duas citações visuais da história da fotografia. Estes foram compostos contrapondo os quatro principais temas que a fotografia tem preferido tradicionalmente: o espaço escolar, os alunos, o professor e as interações entre eles. Nos foto-ensaios que apresentamos em seguida propomos leituras cruzadas entre estes quatro temas. 0 resultado destas interferências visuais $e$ associações livres propõe algumas conclusões visuais para o nosso estudo.

Palavras chave Investigação Educativa baseada nas Artes Visuais, Fotografia, Educação, Artes Visuais. 
Fig 1. Fotoresumen. En el aula. Fotoresumen compuesto por una fotografía digital del autor, y una cita visual literal Fonte: Papo, 2007
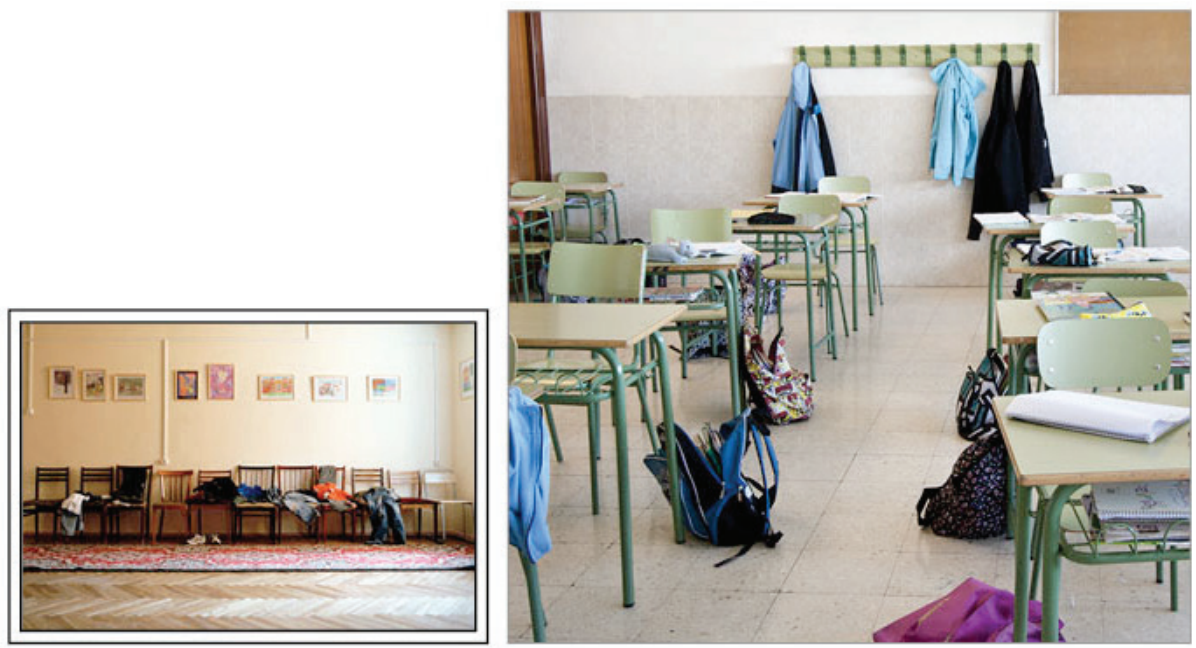

\section{Introducción}

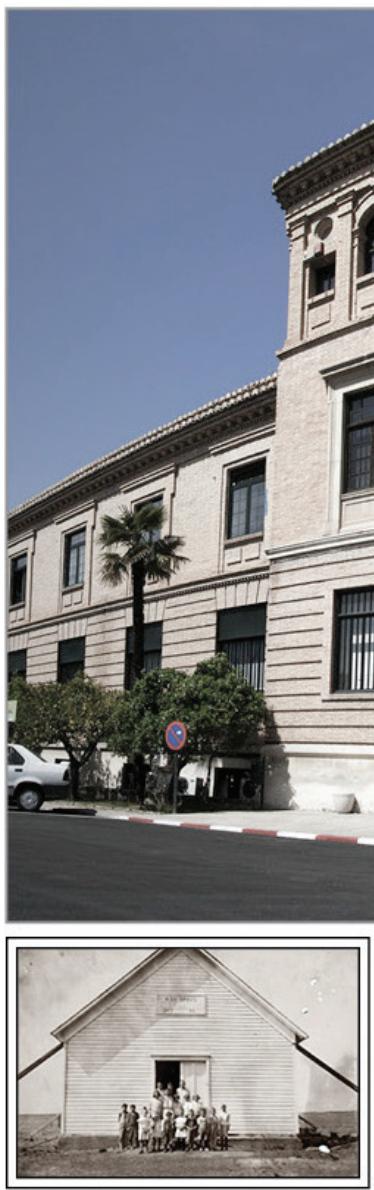

La fotografía documental y la artística se han interesado de forma reiterada sobre la educación desde principios del siglo XX, planteando multitud de cuestiones educativas desde una perspectiva visual. La educación se define fotográficamente a través de relaciones espaciales, metáforas visuales, formas, luces, tonalidades y objetos representados. Los fotógrafos artísticos desvelan y ponen de relieve una serie de claves visuales que 
pueden ser muy interesantes para un análisis cultural del concepto de la educación. Entre estas claves visuales que facilitan estos artistas, destaca la forma en que habitualmente estructuran temáticamente sus trabajos. Los fotógrafos artísticos suelen organizar sus imágenes a cerca de la educación en torno a cuatro ejes temáticos fundamentales: el espacio, las acciones, los docentes y el alumnado.

Estos cuatro temas sirven como ejes principales a la hora de afrontar los problemas, los personajes, las interrelaciones, las instalaciones y los roles que se llevan a cabo en el ámbito del aprendizaje y la enseñanza.

El interés de la fotografía artística por el mundo educativo es visual, y sus imágenes plantean ideas fotográficas sobre los temas que representan. Cada una de las imágenes y el modo en que las presentan plantean intuiciones pedagógicas que aparecen gracias al tono en que son representadas, o que se evidencian por la composición que ha utilizado el artista. De tal modo que las fotografías artísticas proponen nuevos argumentos y nuevas formas de plantear la investigación educativa, especialmente cuando las imágenes son el centro de la investigación.

La naturaleza visual de esta investigación se relaciona directamente con la metodología que utilizamos. La nuestra es una Investigación Educativa Basada en las Artes Visuales que utiliza las estrategias propias de la creación artística como instrumentos y técnicas de indagación. En esta investigación las fotografías son el elemento fundamental a través del cual se plantea y se define el problema, se obtienen e interpretan los datos, se argumenta y se deducen las conclusiones.

Las fotografías que componen el discurso visual de este articulo analizan, comentan, y argumentan las distintas visiones e ideas educativas que los artistas referenciados muestran las citas visuales literales. Así pues, a lo largo de este artículo las imágenes configuran un discurso visual a través del cual exponemos una serie de ideas entorno al espacio educativo y sus actores.

Cada una de las fotografías utilizadas se han obtenido a través de una observación participante iniciada en marzo de 2009 en la Facultad de Ciencias de la Educación de la Universidad de Granada y en el Colegio San Juan Bosco de Granada. A lo largo de este período se han recogido datos visuales in situ, con el objetivo de obtener, analizar, contrastar y organizar los datos de esta investigación. 

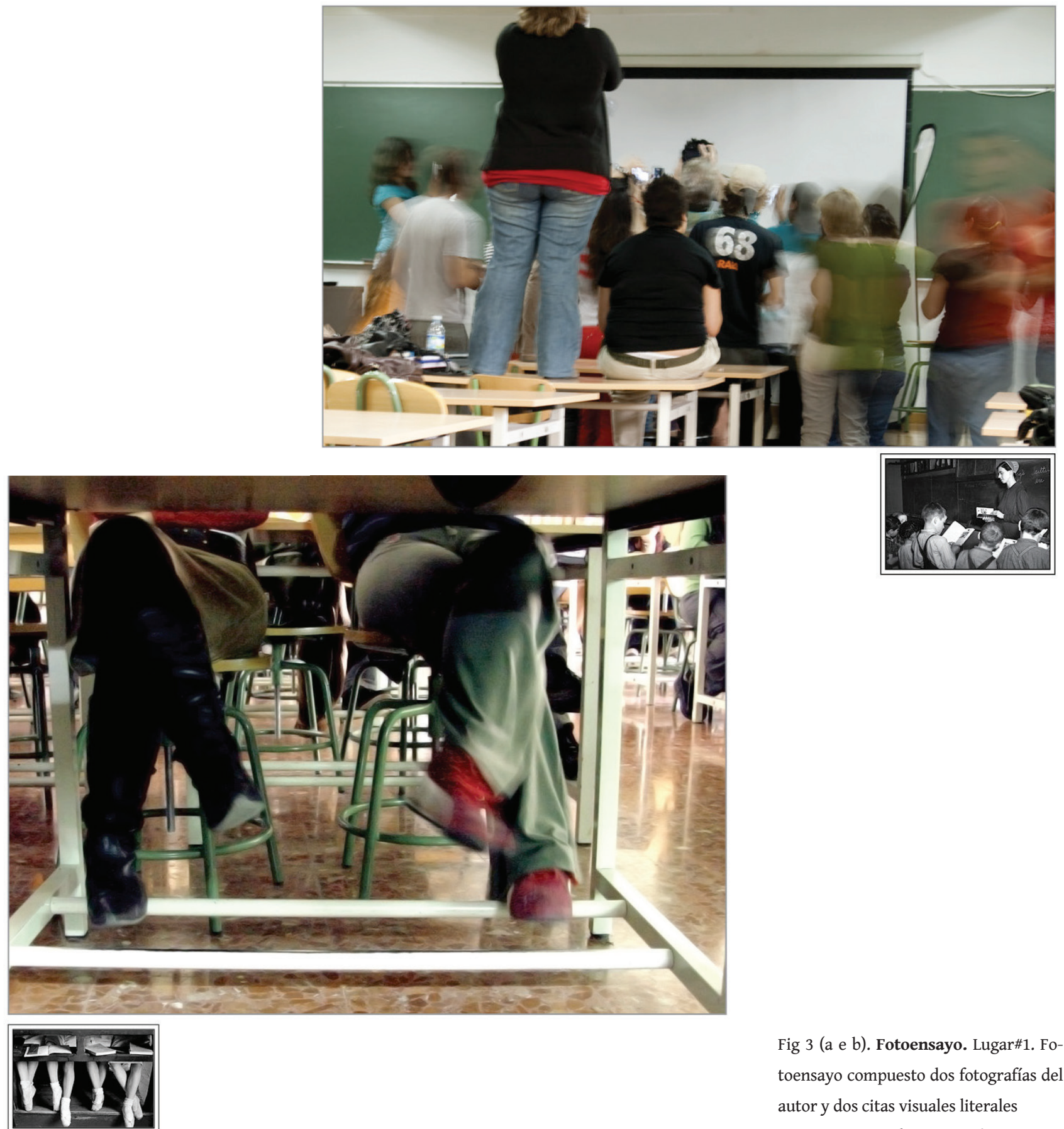

Fig 3 (a e b). Fotoensayo. Lugar\#1. Fotoensayo compuesto dos fotografías del autor y dos citas visuales literales

Fonte: Eisenstaedt, 1934; anónima, 1911 


\section{Fotografía Artística VS Fotografía Documental}

Una imagen fotográfica muestra visualmente un objeto, una persona, una acción, una escena, un lugar. Como si se tarara de un análogo cada imagen fotográfica tiene un referente real. Esta naturaleza referencial de la fotografía es la que justifica la mayor parte de sus funciones sociales como documento. La capacidad de reproducir fielmente la realidad ha posicionado socialmente a la imagen fotográfica como uno de los mejores instrumentos al servicio de la veracidad (BARTHES,1994; CASTELO, 2006; FONTCUBERTA, 2007; FREUND, 2004; SONTAG, 1996).

Sin embargo, una imagen fotográfica también es capaz de representar ideas o conceptos que no son literales traducciones de los objetos presentados. Las fotografías significan no solo por lo que muestran, sino por cómo lo muestran y por lo que ocultan. El autor selecciona un fragmento de la realidad y toma una serie de decisiones técnicas y estéticas que van a condicionar el contenido de la imagen. De este modo la imagen fotográfica puede llegar a trascender la literalidad referencial del objeto representado convirtiéndolo en objeto visual (BERGER, 2007; DEWEY, 2008; EISNER, 2004; ROLDÁN 2010, 2012; SONTAG, 1996). Por lo tanto, no podemos analizar y valorar las fotografías como simples presencias de realidades tal y como se sentiría tentado a hacer Barthes, ni tampoco podemos olvidar su carácter referencial y tratarlas sin más como meras recreaciones imaginarias sin relación con lo real. Las fotografías no son imágenes especulares, ni las cámaras son espejos. Ante un espejo solo vemos nuestra propia imagen si nos situamos frente a él, si una persona se sitúa frente al mismo espejo ve su imagen y no la nuestra; sin embargo, ante una fotografía todo el mundo ve la misma imagen. Una fotografía es una configuración visual estable creada por alguien con una intencionalidad estética y con unos límites semánticos y de lenguaje. Si ante la imagen es peculiar no había lenguaje, ni tampoco límites semánticos salvo los del intérprete, ante una imagen fotográfica el espectador siempre tiene que reconstruir el significado a partir de los límites del lenguaje que el fotógrafo ha impuesto en la imagen (ECO, 1985).

¿Por qué nos interesan las imágenes artísticas sobre la escuela? Fundamentalmente porque los artistas exponen en cada una de sus imágenes una dimensión estética de la realidad capaz de desvelar relaciones, aspectos, detalles, etc., que pueden pasar desapercibidos en otras formas de análisis. (FONTCUBERTA, 2010; ROLDÁN, 2003).

Frente a la fotografía artística nos encontramos con multitud de imágenes que reducen a la mínima expresión esta dimensión estética, simplificando el lenguaje fotográfico a la mera representación en la escena escolar de objetos, espacios, personas o acciones. Estas imágenes testimoniales que podemos encontrar en los medios de comunicación, en las investigaciones educativas convencionales y en las propias actividades escolares, tienen un contenido intelectual limitado en comparación con las fotografías 
artísticas ya que los artistas depuran profundamente su lenguaje, cuidan las relaciones simbólicas que pueden surgir de sus imágenes y controlan las posibles asociaciones que el espectador realiza frente a su obra.

Por ello la fotografía artística puede aportar a la investigación y cultura educativa ideas e intuiciones a las que la fotografía documental no es capaz de llegar.
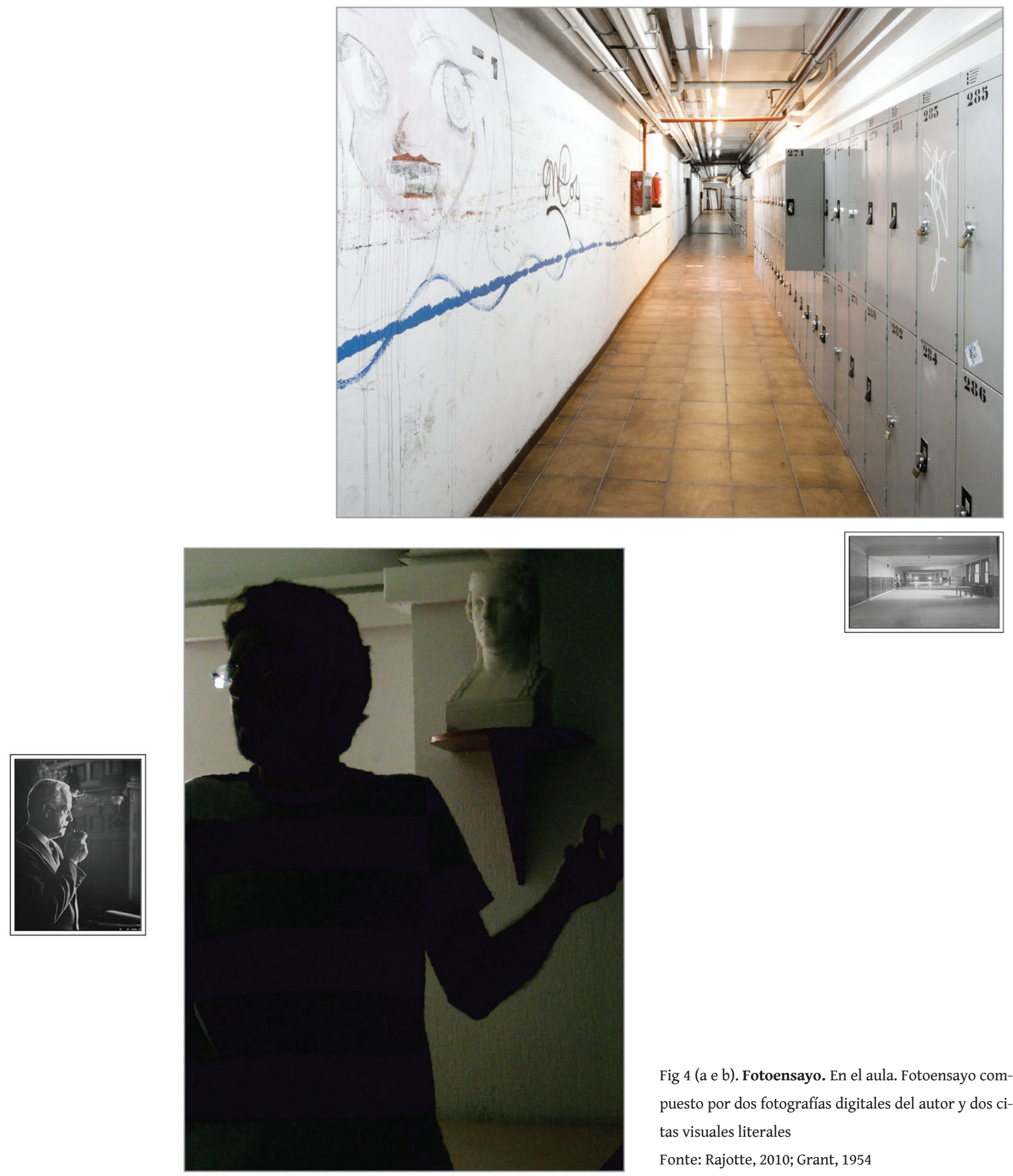

Fig 4 (a e b). Fotoensayo. En el aula. Fotoensayo compuesto por dos fotografías digitales del autor y dos citas visuales literales

Fonte: Rajotte, 2010; Grant, 1954 


\section{Principales temas educativos en la Fotografía Artística}

"Una representación o descripción en función de cómo clasifica y es clasificada, puede establecer o señalar conexiones, analizar objetos y organizar el mundo." (GOODMAN, 1976:48)

La fotografía artística se ha sentido atraída por el mundo escolar, su entorno y actividades desde muy pronto pudién dose encontrar en los archivos fotográficos y las bibliotecas multitud de trabajos artísticos sobre la educación. Autores como Lewis Hine (1908-1916), Walker Evans (1941), Robert Doisneau (1956), Margaret Bourke-White (1937-1956), Alant Grant (1956), Leonard McCombe (1969), Ted Tahi (1989-2004), Nicholas Nixon (1998), Kim Manresa (2003), Tomoko Sawada (2004), Julian Germain (2004), o James Rajotte (2010) entre otros, han generado un amplio archivo fotográfico de la educación.

Cada uno de estos trabajos artísticos proponen una mirada concreta sobre la educación. Desde su control sobre las claves del lenguaje fotográfico, los autores se han cuestionado de forma exclusivamente visual y sin el apoyo de explicaciones textuales, los aspectos simbólicos, metafóricos, profesionales, psicológicos, emocionales, sociales, antropológicos, estéticos, formales y conceptuales entorno a la educación y sus ambientes, situaciones y protagonistas.
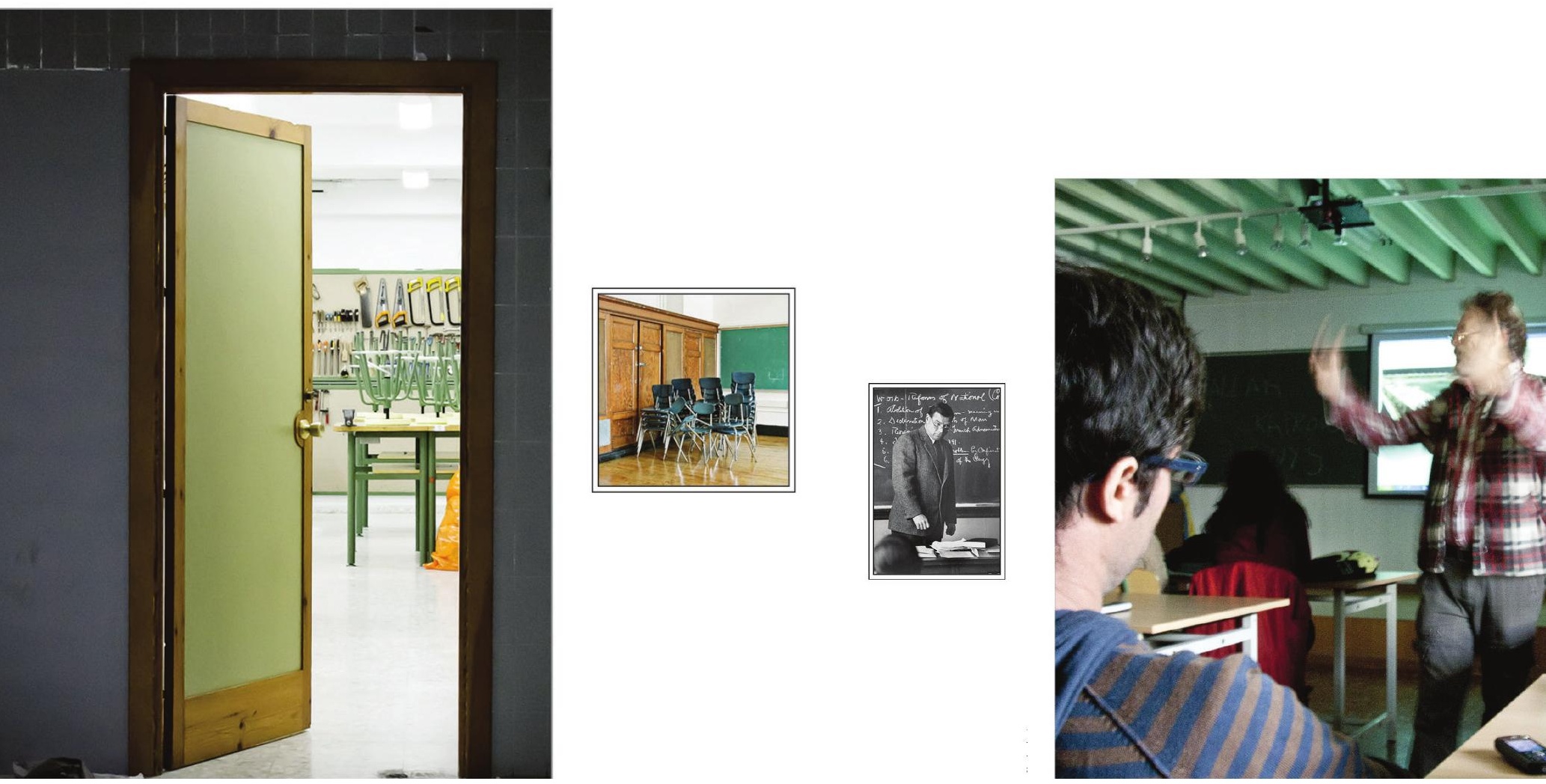

Fig 5 ( $\mathrm{a} \mathrm{e} \mathrm{b).} \mathrm{Fotoensayo.} \mathrm{Relaciones.} \mathrm{Fotoensayo} \mathrm{compuesto} \mathrm{por} \mathrm{dos} \mathrm{fotografías} \mathrm{digitales} \mathrm{del} \mathrm{autor} \mathrm{y} \mathrm{dos}$ citas visuales literales | Fonte: Grant, 1954; McCombe, 1969 
Para esta investigación hemos realizado una búsqueda documental e histórica de las principales colecciones de imágenes fotográficas que existen sobre la educación tanto en archivos, publicaciones, museos o instituciones, e incluso en las páginas webs de los artistas. A partir del análisis de este vasto y heterogéneo conjunto de imágenes, se ha podido concluir que hay cuatro temas fundamentales que aparecen de forma recurrente en las imágenes recopiladas: los espacios, las acciones educativas, los docentes y el alumnado. Estos temas fundamentales sirven como elementos organizadores de las imágenes educativas.

El espacio

Uno de los temas fotográficos fundamentales es el espacio educativo. El edificio cuando es retratado sólo aparece vacío, aparentemente inerte, centrando el protagonismo en aquellos aspectos que lo determinan como objeto o lugar: la forma, la estructura, el mobiliario, la luz que lo moldea, etc. En este tipo de imágenes vacías, los espacios se presentan aislados con el objetivo de convertirlos en tema, en motivo fotográfico a través del cual contextualizar y definir lo educativo. Así, el espacio escolar (o, de forma más general, el espacio educativo) se interpreta como un personaje en sí mismo, en el que pueden o no aparecer los individuos (EVANS, 1941; RAJOTTE, 2010).

En otro tipo de imágenes, el centro educativo es representado junto a los individuos que lo transitan y que lo ocupan como un contexto, como un objeto o como un ambiente. En ocasiones, los artistas utilizan el edifico escolar como una excusa, en ocasiones como un elemento de comparación, y en ocasiones, se convierten incluso en el protagonista absoluto, por sus cualidades constructivas o volumétricas, por su interacción con las personas o por su fisonomía peculiar. Cuando es el objeto o el espacio el protagonista, las personas quedan en un segundo lugar (HINE, 1916; MCCOMBE, 1969).

\section{Acciones o procesos educativos}

La fotografía artística mayoritariamente acude al interior del aula en busca de acciones educativas, primero desde lo tópico y luego fotografiando aquello que está detrás de lo obvio, los objetos y su participación en los procesos, los gestos, los movimientos, las distancias, las actitudes que se reflejan en el juego pedagógico. (MANRESA, 2003). En muy pocas ocasiones, las acciones son fotografiadas fuera del ámbito del centro escolar, porque sin ése referente perderían interés como lugares comunes y símbolos del concepto de educación. 
Las acciones se desarrollan entorno a objetos y a personas. Son siempre el resultado de una necesidad o de una intervención y sintetizan los momentos culmen del proceso de enseñanza o aprendizaje. Los artistas a menudo tratan de escoger ése momento decisivo y ello ha convertido algunas de sus imágenes en decisivas en la construcción actual del concepto de educación. (HINE, 1916; COLES \& NIXON, 1998)
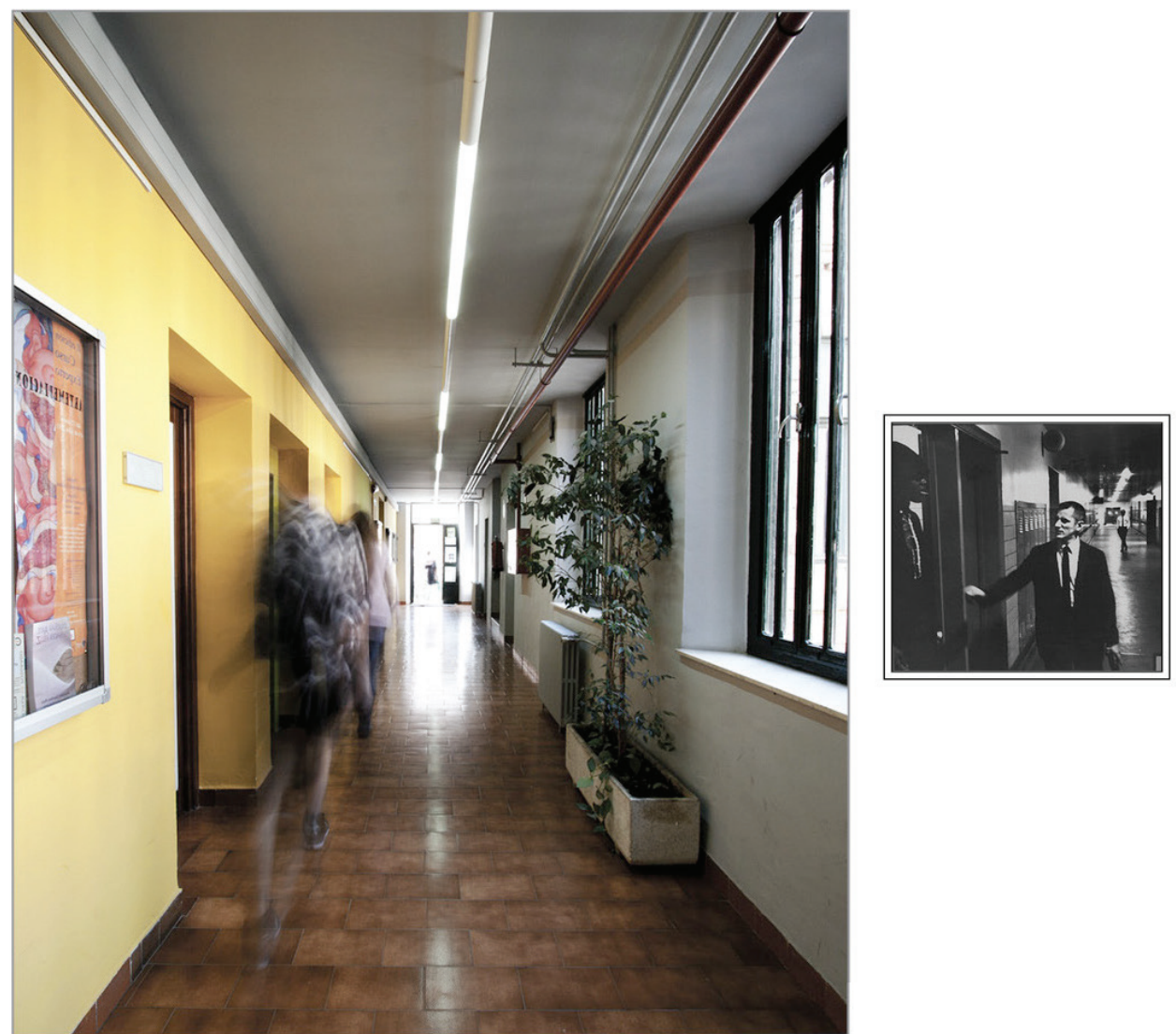

Fig 6 (a e b). Fotoensayo. Momentos. Fotoensayo compuesto por dos fotografías digitales del autor y dos citas visuales literales | Fonte: Schatz, 1991; Coles \& Nixon, 1998
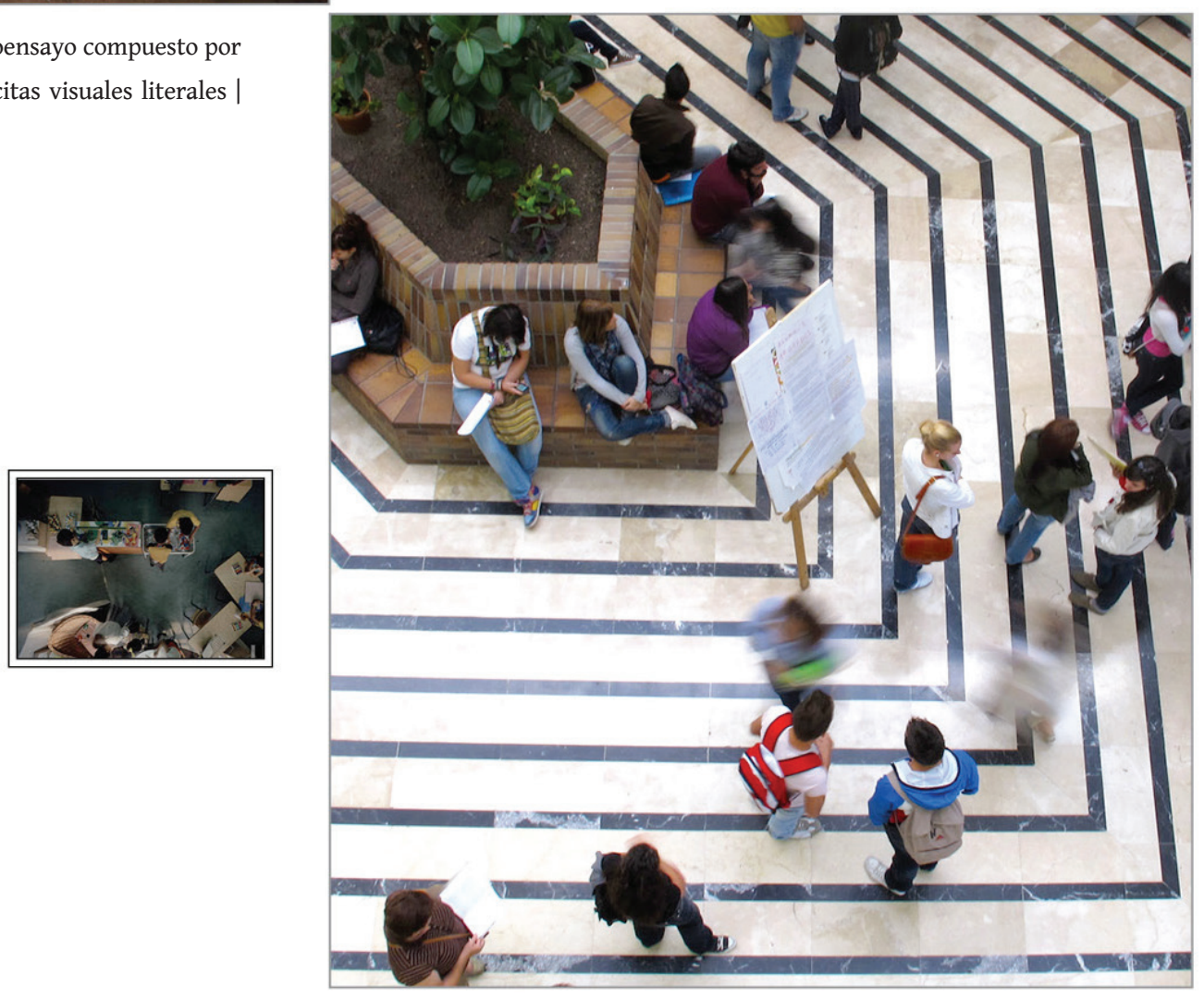


\section{El profesorado}

Los docentes son retratados a través de sus distintas actitudes y emociones. Aparecen en contextos formales-académicos, en actitudes típicas de la docencia (explicando, escribiendo en la pizarra, junto a los escritorios del alumnado, etc.), y solo en algunas ocasiones son retratados fuera del aula (los pasillos, o sus despachos). Los docentes son fotografiados de forma convencional, profundizando poco en aquellos aspectos que pueden definir plenamente al profesorado. En algunas ocasiones, los fotógrafos acuden al contexto personal de los docentes con el objetivo de humanizarlos a través de sus quehaceres cotidianos, alejados del rol de docente; sin embargo, el ámbito personal no es una imagen recurrente a la hora de plantear fotográficamente al docente (GRANT, 1954). Mayoritariamente, el profesorado es presentado en su rol profesional a través de convenciones creadas por asociación con el lugar, los objetos, el alumnado o el instrumental típico de un aula.

\section{El alumnado}

Es el tema más recurrente en las fotografías de escuela. El alumnado es el foco principal de los discursos visuales en torno a la educación. Los fotógrafos artísticos tratan de reconocer y personificar las distintas actitudes, actividades, producciones e interrelaciones entorno al alumnado, buscando aquellos elementos que definan al estudiante como individuo (COLES \& NIXON, 1998; EISENSTAEDT, 1934). Es muy utilizada la relación corporal con los muebles escolares y con los demás compañeros. Se puede decir que se ha descrito al alumnado de forma similar a como se han descrito a adultos en el terreno profesional, relacionándolos con objetos, instrumentos y espacios tanto como con actitudes y relaciones en ése ámbito.
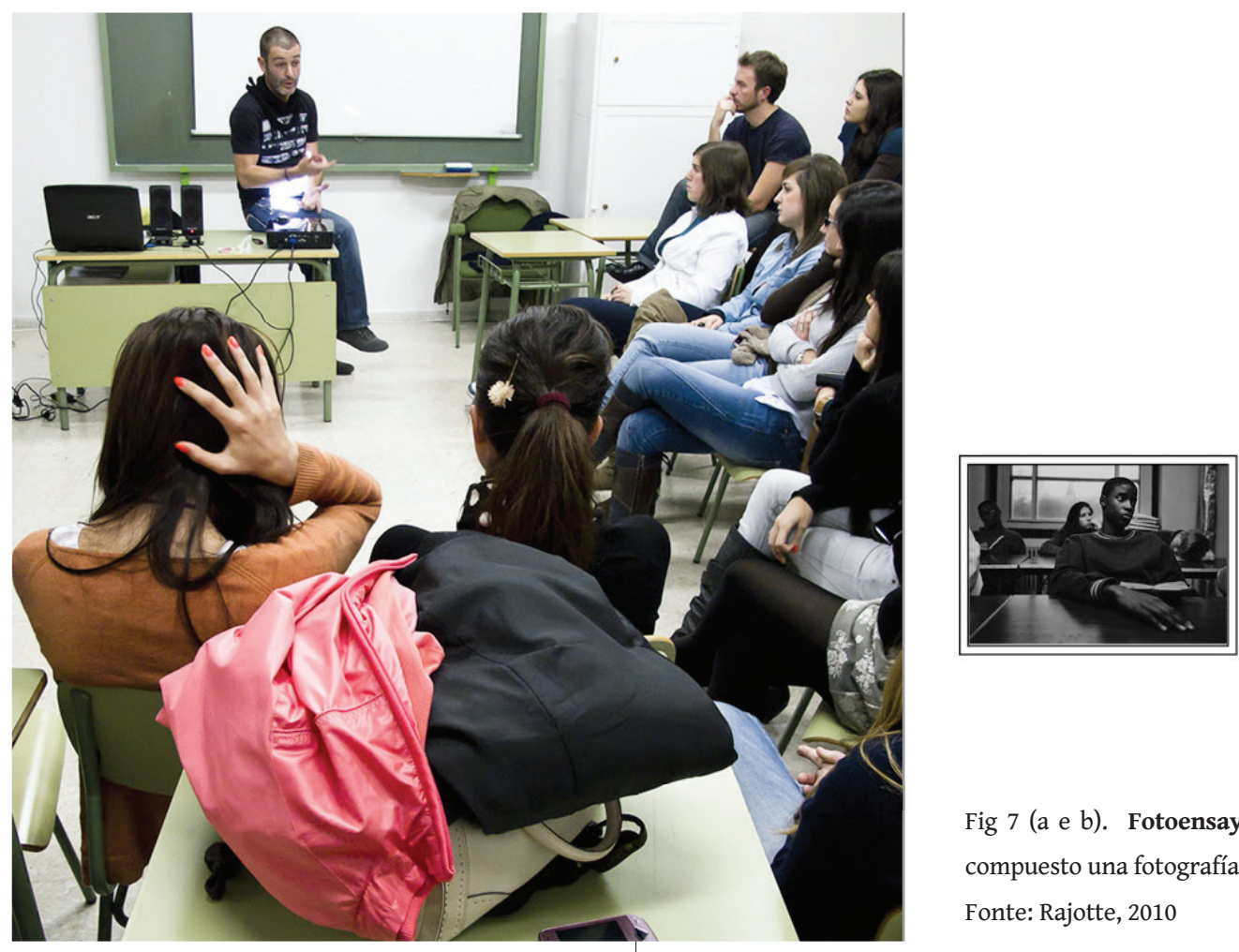

Fig 7 ( $a$ e b). Fotoensayo. Espacios educativos fotográficos. Fotoensayo compuesto una fotografía del autor y una cita visual literal 

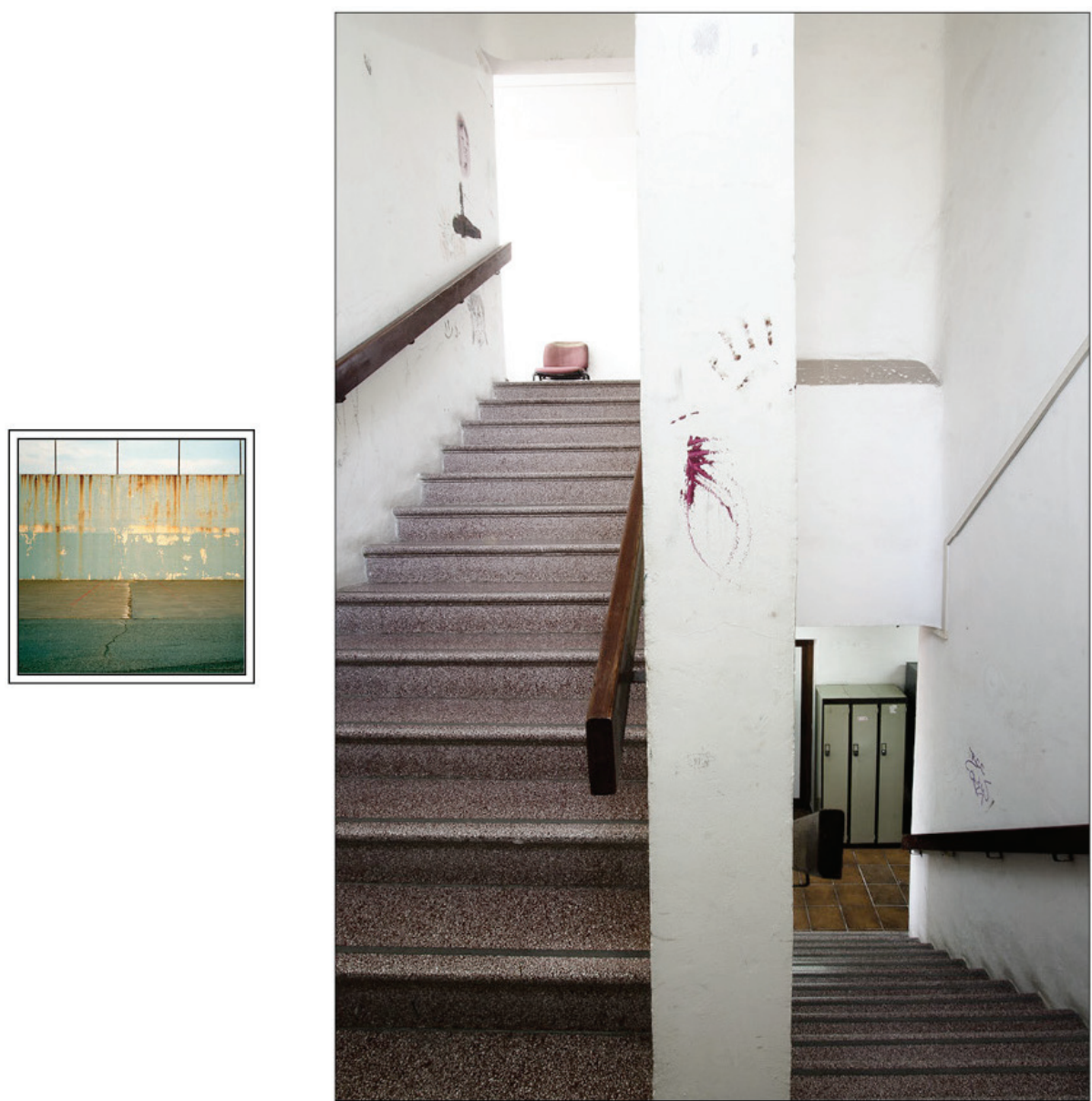

\section{Investigación basada en las Artes Visuales}

El análisis que se presenta en este artículo indaga en torno a cómo la fotografía artística ha afrontado lo educativo generando una serie de pautas para el estudio visual de la educación. Para establecer un marco lógico y coherente respecto al tema investigado, la elección de una metodología que trabaje en los mismos términos es determinante.

El objetivo de este estudio basado en las artes es realizar un fotoensayo que muestre visualmente referencias de artistas que han fotografiado la educación junto con imágenes construidas en entornos educativos. En este trabajo, por tanto, hemos trabajado a partir de las Metodologías Artísticas de Investigación, y en concreto, desde la Investigación Educativa Basada en las Artes Visuales. Este enfoque metodológico utiliza las imágenes visuales en el ámbito de la investigación principalmente por su contenido estético y no por los datos o informaciones relativas al tema que represen- 
tan. La Investigación Educativa Basada en las Artes Visuales trata de cuestiones visuales en términos visuales, intentando evitar traducciones entre lenguajes, ya que se sirve de las imágenes y de sus formas propias de organización de las mismas para indagar en torno a las imágenes e ideas visuales.

En este caso presentamos a lo largo de todo el capítulo, un fotoensayo organizado a partir de pares de imágenes que se han realizado en distintos entornos educativos y que se apoyan en diversas citas visuales de reconocidos artistas fotógrafos. Para este estudio se ha realizado un análisis fotográfico tomando como referencia aquellos artistas que han trabajado de forma reiterada sobre la educación. Para ello se ha realizado una observación participante que ha permitido estar presente en espacios educativos observando, analizando y contrastando visualmente los datos.

La utilización durante el proceso de investigación de estrategias fotográficas utilizadas por los autores analizados ha contribuido a que el estudio pueda incluir elementos comparativos y estéticos sobre los diferentes temas considerados. La realización de fotografías durante el proceso de análisis, estudio y elaboración de ideas, ha permitido trabajar en el mismo plano del objeto investigado: las fotografías educativas.

\section{Conclusiones no visuales}

Este estudio presenta imágenes fotográficas para hablar de realidades visuales. A través de nuestras fotografías, tratamos de colaborar en la revisión crítica de los conceptos asociados a la educación. Ya que las imágenes son el foco principal de estudio, la utilización metodológica de la Investigación Educativa Basada en las Artes Visuales permite afrontar este estudio con los mismos instrumentos, evitando traducciones que puedan llevar a la interpretación errónea de los datos obtenidos en la investigación. A lo largo de este articulo los fotoensayos se constituyen no solo como instrumentos expositivos y argumentativos, sino que, dada su naturaleza metodológica, constituyen argumentos tanto como conclusiones visuales que estructuran y definen el interés de la investigación.

La fotografía se toma frecuentemente en nuestra sociedad como un documento fiable para constatar una acción, un suceso, un individuo, etc. Cuando se toman las imágenes como referentes, obviando su naturaleza visual, y por tanto cultural, se está pasando por alto la naturaleza misma de la fotografía: la fotografía es un lenguaje sometido regulaciones que determinan su mensaje. El mensaje puede ser connivente con los modelos aceptados sobre la educación o puede ser crítico, puede ser afirmativo o negativo, puede ser estimulante o adormecedor, puede responder a cuestiones $o$ puede evidenciar nuevas preguntas. 
Los trabajos fotográficos desarrollados por la fotografía artística son esenciales ya que sus autores controlan el lenguaje fotográfico, lo que les sitúa como referencias fundamentales a la hora de afrontar visualmente lo educativo, ofreciendo modelos de acercamiento, presentación y representación visual de lo educativo.

Desde las cuatro grandes áreas temáticas se establecen infinitas temáticas menos repetidas, pero igualmente relevantes que dotan de matices y contenidos a los temas fundamentales. Sin embargo, la estructuración de estos temas educativos bajo cuatro grandes ejes fundamentales resulta determinante ya que facilita el análisis y la elaboración de conclusiones visuales.

En torno a la clasificación presentada en este artículo se han seleccionado y contrapuesto algunas de las imágenes más interesantes que visualizan algunos aspectos acerca de los problemas educativos más significativos. Las imágenes producidas desde la fotografía artística desvelan aspectos que pueden ser interesantes para la investigación educativa, y que con otros instrumentos metodológicos como los textuales son más difíciles de visualizar, como por ejemplo la comunicación no verbal presente en el proceso enseñanza-aprendizaje, la individualidad de las personas, etc.

De tal modo que, utilizando estos cuatro grandes temas educativos y los subtemas elaborados desde el análisis de la fotografía artística, se establecen unos modelos visuales de análisis que sirven para la investigación educativa. Estos modelos son efectivos como referentes para el análisis visual de un entorno educativo, de una acción educativa o de los agentes educativos, ya que proponen una serie de ejes que sirven para afrontar y ordenar visualmente la educación.

Las imágenes fotográficas educativas producidas desde el arte se sirven de multitud de estrategias a través de las cuales establecer y plantear de la educación, siendo muy efectivos ya que amplían y enriquecen el concepto de educación.

Conceptos que no existieron más allá de los límites de las propias imágenes, pero que existen visualmente y con ello, pueden transformar nuestros conceptos acerca.

\section{Referencias}

ANÓNIMA. Northwestern High School, main corridor, Detroit, Mich. Library of Congress, www.loc.gov/pictures/; http://www.loc.gov/pictures/item/det1994018823/PP/ [18/11/2009]. 1911.

ARNHEIM, R. Consideraciones sobre la educación artística. Barcelona: Paidós, 1993. BARTHES, R. La cámara lúcida. Nota sobre la fotografía. Barcelona: Paidós, 1994.

BERGER, J. \& MOHR, J. Otra manera de contar. Barcelona: Gustavo Gili, 2007.

BERGER, J. Mirar. Barcelona: Gustavo Gili, 2001.

CASTELO, L. Del ruido en el arte. Madrid: H. Blume, 2006.

COLES, L. \& NIXON, N. School. Vancouver: Bulfinch Pr., 1998. 
DEWEY, J. El arte como experiencia. Barcelona: Paidós, 2008.

DUBOIS, P. El acto fotográfico. Barcelona: Paidós, 1986.

EISNER, E. El arte y la creación de la mente. Barcelona: Paidós, 2004.

EISNER, E.. \& DAY, M. D. Handbook of research and policy in art education. Mahwah, New Jersey: Lawrence Erlbaum Associates, 2004.

FONTCUBERTA, J. El beso de Judas. Fotografía y verdad. Barcelona: Gustavo Gili, 2007. FREUND, G. La fotografía como documento social. Barcelona: Gustavo Gili, 2004. GOODMAN, N. Los lenguajes del arte. Barcelona: Seix Barral, 1976.

GOODMAN, N. Maneras de hacer mundos. Madrid: La Balsa de la Medusa, 1990.

GRANT, A. 'Headmaster of Hotchkiss Prep. School, George Van Santvoord, smoking pipe'. LIFE photo archive, 1954. Disponível em: http://images.google.com/hosted/life/3e4191d69987e91b.html e em: http://images.google.com/hosted/life/d4ce748e9b7573b6. html. Acesso em: 12/12/2011.

HINE, L.W. Oct. 10, 1916. Comanche County, Oklahoma. Disponível em: http://www.shorpy. com/node/1689?size=_original.

La cámara de Pandora. La fotografía después de la fotografía. Barcelona: Gustavo Gili, 2010. MARÍN, R. Investigación en educación artística: temas, métodos y técnicas de indagación sobre el aprendizaje y la enseñanza de las artes y culturas visuales. Granada: Universidad de Granada, 2005.

MARÍN, R.; ROLDÁN, J. 'Photo essays and photographs in visual arts- based educational research'. International Journal of Education through Art 6: 1, pp. 7-23, 2010. DOI: 10.1386/ eta.6.1.7_1.

MCCOMBE, L. 'African American student at Woodward High School talking with hallway patrol'. LIFE photo archive, 1969. Disponível em: http://www.gstatic.com/hostedimg/ b8c2141c13d06a19_large e em: http://images.google.com/hosted/life/f?imgurl=b8c2141c13d06a19. Acesso em: 06/12/2011.

PAPO, R. Auditions Day at the Vaganova Ballet Academy, St. Petersburg, Russia, 2007 (\#14). Disponível em: http://www.rachelpapo.com/, http://www.rachelpapo.com/perfect13.html. Acesso em: 23/08/2009.

RAJOTTE, J. High school \#10, 2010. www. jamesrajotte.net. Disponível em: http://jamesrajotte.net/wp-content/uploads/11.jpg e em: http://jamesrajotte.net/photographs/high-school/\#10. Acesso em: 19/06/2011.

RAJOTTE, J. High school \#7, 2010. www. jamesrajotte.net. Disponível em: http://jamesrajotte.net/wp-content/uploads/53660013.jpg e em: http://jamesrajotte.net/photographs/ high-school/\#7. Acesso em: 17/07/2011.

ROLDAN, J. 'Emociones reconocidas. Formación, desarrollo y educación de las experiencias estéticas'. En MARÍN, R. (COORD.). Didáctica de la educación artística para primaria. Madrid: Pearson, 2003.

ROLDAN, J. Diálogos de imágenes: creación artística en papel. Granada: EUG, 2007. ROLDÁN, J.; HERNÁNDEZ, M. El otro lado. Fotografía y pensamiento visual en las culturas universitarias. Aguascalientes (México) y Granada (España): Universidad Autónoma de Aguascalientes y Universidad de Granada, 2010.

SONTAG, S. Sobre fotografía. Barcelona: Edhasa, 1996.

Recebido: 15 de fevereiro de 2020.

Aprovado: 30 de abril de 2020 . 